\title{
Seasonal Change in the Germination of Heteromorphic Achenes of Bidenspilosa
}

\author{
Hidehiro Inagaki ${ }^{*}$, Takehiro Kinoshita \\ Shizuoka university, Fujieda, Japan.
}

How to cite this paper: Hidehiro Inagaki, Takehiro Kinoshita. (2021) Seasonal Change in the Germination of Heteromorphic Achenes of Bidenspilosa. International Journal of the Science of Food and Agriculture, 5(1), 91-96.

DOI: 10.26855/ijfsa.2021.03.013

Received: December 24, 2020

Accepted: January 25, 2021

Published: February 6, 2021

*Corresponding author: Hidehiro Inagaki, Shizuoka university, Fujieda, Japan.

Email: inagaki.hidehiro@shizuoka.ac.jp

\begin{abstract}
Bidens pilosa is a noxious weed species. Its capitulum is heteromorphic achenes divided into central and peripheral achenes. Central achenes are longer, with thorns facing outward from the capitulum, whereas peripheral achenes are shorter, with thorns facing inward. In the present study, we hypothesized that dimorphic achenes of $B$. pilosa have different seed dispersal strategies, and we compared the difficulty of their detachment and seasonal changes in their germination in order to identify the differences in these strategies. Our results revealed that central achenes were significantly easier to detach than peripheral achenes, suggesting that central achenes may be used for dispersal to farther areas, and peripheral achenes may be used for dispersal to neighboring areas. Furthermore, central achenes showed relatively higher germination rates than peripheral achenes. Only the central achenes showed high germination in dark conditions at $20^{\circ} \mathrm{C}$ in May. In contrast, peripheral achenes showed high germination in dark conditions at $20^{\circ} \mathrm{C}$ and $25^{\circ} \mathrm{C}$ in July. This suggested that central achenes germinated first (in May), and peripheral achenes germinated later in the summer. Our results also indicated that the achenes of B. pilosa showed seasonal changes in photoblastic germination, i.e., both central and peripheral achenes showed light-induced germination in March and dark-induced germination from May to September. Dimorphic achenes and seasonal change in dormancy and photoblastic germination cause asynchronous emergence of plants, making it difficult to control the spreading of B. pilosa.
\end{abstract}

\section{Keywords}

Bidenspilosa, heteromorphic achenes, seed dispersal, germination, photoblastic

\section{Introduction}

In weed species, asynchronous emergence and lengthy emergence periods are important factors that increase the difficulty of weed management. Seed heteromorphism and polymorphism are one of the causes of asynchronous emergence of weed species [1, 2]. It is known that many Asteraceae species have different achene morphs within a single capitulum [3-5]. In particular, Bidens species, such as Bidensbipinnata [6], B. frondosa [7], B. gardneri [8], and B. odorata [9], which belong to the family Asteraceae, have obvious heteromorphic achenes.

Bidenspilosa is a noxious weed species with heteromorphic achenes [2, 10, 11]. It is a common annual weed species [12] which originates in temperate and tropical America, and has been expanding its range across Europe since the 19th century [13]. This species was naturalized in Japan hundreds of years ago. Currently, this species is widely distributed in warm regions of Japan, and in Japan, it has been designated as an alien species requiring attention [12]. Seed dispersal mode of $B$. pilosa is zoochory, and its achenes have thorns for attaching to different surfaces, such as animal bodies.

Dimorphic achenes of $B$. pilosa include central and peripheral achenes [10, 11]. Central achenes are longer, with thorns facing outward from the capitulum, whereas peripheral achenes are shorter, with thorns facing inward from the 
capitulum. Therefore, compared with peripheral achenes, the central achenes are more easily attached to different surfaces. Indeed, it has been observed that central achenes detach from the capitulum earlier than peripheral ones, which often remain on the capitulum even during winter. This suggests that dimorphic seeds might have a shared role as migrating and non-migrating seeds. In addition, there is difference in seed germination among the dimorphic achenes of $B$. pilosa $[2,10,11]$. The survival of annual weed species often relies on mechanisms that ensure the appropriate timing of germination and that germination occurs in a suitable habitat, which will allow seedling establishment [14]. Differences in mobility and germination between the dimorphic achenes of $B$. pilosa are considered to be important for the maintenance and dispersion of their seeds.

In the present study, we hypothesized that there are differences in seed dispersal strategies between the dimorphic achenes of B. pilosa. To investigate this, we compared the difficulty of detachment of the two achene morphs and investigated the seasonal change in their germination.

\section{Materials and Methods}

\subsection{Seed material and achene size}

On March 1, 2016, freshly matured central and peripheral achenes of B. pilosa were collected from a population in the riverhead of Abe River (Shimokawahara, Shizuoka, Japan) and stored at room temperature $\left(18-33^{\circ} \mathrm{C}\right)$ until further analyses. We measured the length of 300 central achenes and 300 peripheral achenes, and of each achene type, three groups of 100 achenes were weighed on an analytical balance (0.1 mg accuracy) (Mettler Toledo AB204, Switzerland) to determine the average achene mass.

\subsection{Testing the ease of detachment of dimorphic achenes}

Plant samples with matured achenes were collected from the field of Shizuoka University (Kariyado, Fujieda, Japan) on November 2, 2016. From each capitulum, one achene was fixed with cellophane tape on the plate of an electronic balance (0.1 mg accuracy) (Mettler Toledo AB204, Switzerland) and weighed. We pulled up each achene from plate of electronic balance, and the difference between the weight at the moment when an achene was pulled up and the original weight (g) was regarded as detachment difficulty. In total, 37 central achenes and 26 peripheral achenes were tested.

\subsection{Seasonal change in germination of dimorphic achenes}

Mature dimorphic achenes of B. pilosa were subjected to a germination test on March 1, May 6, July 1, September 2, and November 2, 2016. Three replications of 30 dimorphic achenes were set on a filter paper in a Petri dish with a diameter of $90 \mathrm{~mm}$. The germination test was performed at 25,20 , and $15^{\circ} \mathrm{C}$ in dark and light conditions (12/12 hours). Each test was conducted for five days.

\subsection{Germination and data analysis}

The arcsin transformed germination proportions obtained from germination rate data were subjected to the analysis of variance using the BellCurve for Excel 5.0 software (Social Survey Research Information Co., Ltd, Tokyo). After conducting this analysis, Tukey's multiple range test was used to detect significant differences among the treatments with a probability of $95 \%(\alpha=0.05)$.

\section{Results}

\subsection{Achene size}

Two morphs (central and peripheral achenes) could be distinguished within one capitulum of B. pilosa (Figure 1). Central achenes were elongated, with the length of $10.3 \pm 1.8 \mathrm{~mm}$, and they were significantly longer than peripheral achenes, whose length was $7.5 \pm 1.5 \mathrm{~mm}(\mathrm{P}<0.01$; Table 1$)$. The weight $(100$-achene weight) of the central achenes was $0.19 \pm 0.00 \mathrm{~g}$, which was significantly higher than that of the peripheral achenes $(0.17 \pm 0.00 \mathrm{~g})$.

Table 1. Comparison of the mass (hundred-achenes weight) and length of freshly matured central and peripheral achenes of Bidens pilosa (mean \pm SD)

\begin{tabular}{ccc}
\hline & A chene mass $(\mathrm{g})$ & Achene length(mm) \\
\hline Central & $10.3 \pm 1.8^{*}$ & $0.19 \pm 0.00^{* *}$ \\
Periphera1 & $7.5 \pm 1.5$ & $0.17 \pm 0.00$ \\
\hline
\end{tabular}

**indicates significant difference between central achenes and periphenial achenes at $1 \%$ lever by t-test. 


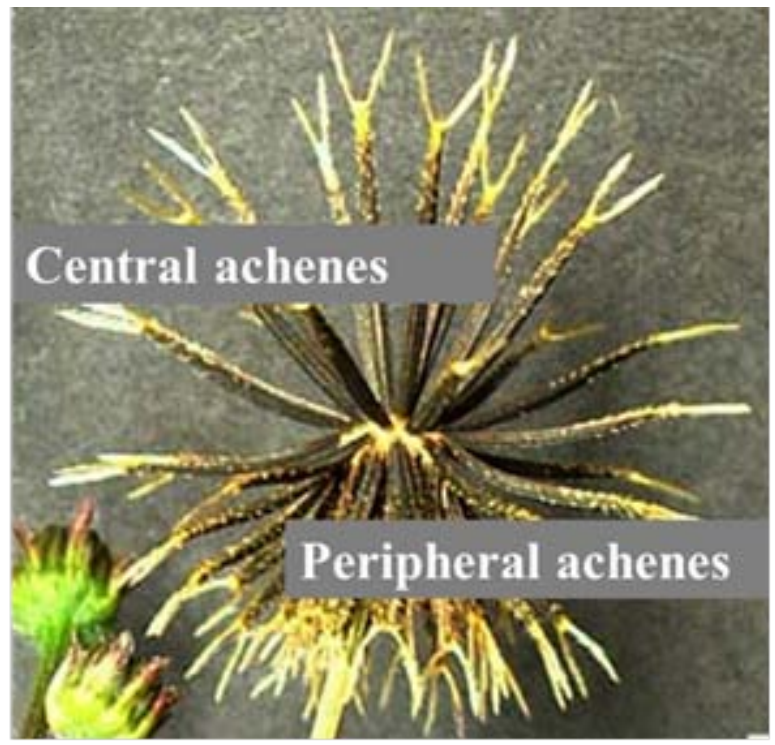

Figure 1. Two achene morphs (central and peripheral achenes) distinguishable within one capitulum of Bidens pilosa.

\subsection{Difficulty of detachment of dimorphic achenes}

Figure 2 shows the difference in the difficulty of detachment between central and peripheral achenes. The value of detachment difficulty of the central achenes was $37.6 \mathrm{~g}$, which was statistically lower than that of peripheral achenes (91.7 g; P 0.01).

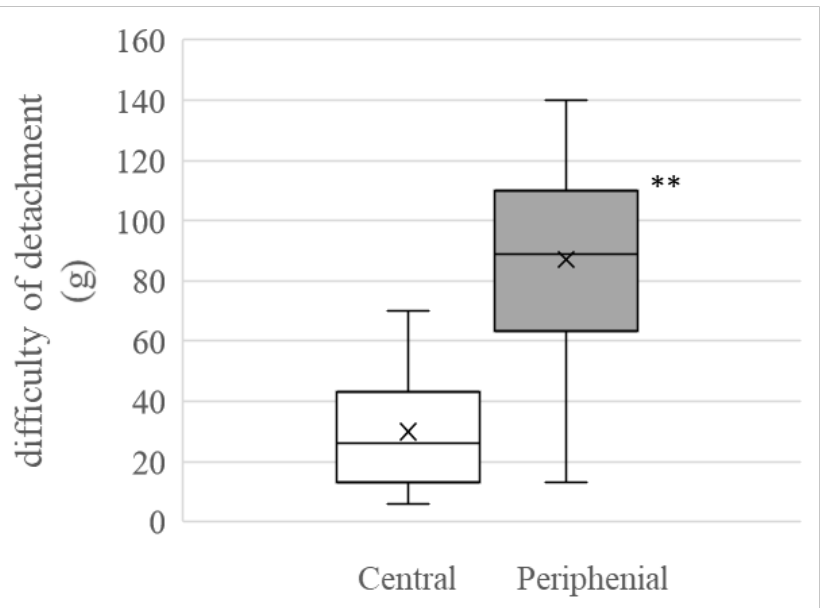

Figure 2. The difference in the difficulty of detachment (g) of central achenes and achenes of Bidenspilosa. The notches on the box plots indicate an $\sim 95 \%$ confidence interval of the median calculated as median $\pm 1.5 \times \operatorname{IQR} / \sqrt{ }(\mathrm{n})$, with IQR (inter quartile range) being the difference between the third and first quartiles (** indicates a significant difference at $1 \%$ level according to the t-test).

\subsection{Seasonal change in the germination of dimorphic achenes}

In March, at the temperature of $25^{\circ} \mathrm{C}$ and in light conditions, the germination rates of both central and peripheral achenes were high (Figure 3, left). There was no difference in the germination rate between central and peripheral achenes under light conditions. On the other hand, under dark conditions, the germination rate of the central achenes was higher than that of the peripheral achenes. The germination rate of both central and peripheral achenes decreased in May compared to the germination rate in March, and the difference between light and dark conditions was not observed at this time. In July, the germination rates under dark conditions increased in both central and peripheral achenes, and the germination rate of peripheral achenes was significantly higher than that of central achenes. In September, their germination rates tended to increase under both light and dark conditions, and the germination rate of both morphs was higher in the dark conditions than in the light conditions. In addition, in September, the germination rate of central achenes was higher than that of peripheral achenes under both light and dark conditions. In November, there was no 
difference between their germination under light and dark conditions and between the germination of central and peripheral achenes, and their germination rates were high in both light conditions.

In March, the germination rate showed the same tendency at $20^{\circ} \mathrm{C}$ and at $25^{\circ} \mathrm{C}$ (Figure 3, middle), and the germination rate of both central and peripheral achenes was higher under light conditions than under dark conditions. In addition, in March, under light conditions, the germination rate at $20^{\circ} \mathrm{C}$ was slightly higher than that $25^{\circ} \mathrm{C}$. In May, at $20^{\circ} \mathrm{C}$, only central achenes in the light condition showed high germination rate. There was no difference in the germination rate among these other three test plots. From July onwards, both central and peripheral achenes showed high germination rates in dark conditions, and there was no significant difference between their germination rates. On the other hand, in July and September, the germination rate of both achene morphs was lower in light conditions than in dark conditions. When compared, in these two months, the germination rate of central achenes was higher than that of peripheral achenes. Under light conditions in November, there was no difference in the germination rate between central and peripheral achenes.

In the conditions of $15^{\circ} \mathrm{C}$ (Figure 3, right), almost no seed germination was obtained, but a slight increase in germination rate was observed from March to September. Although germination was observed in all test plots in November, the germination rate of peripheral achenes the light conditions was $31.1 \%$, which was significantly lower than that in the other three test plots.

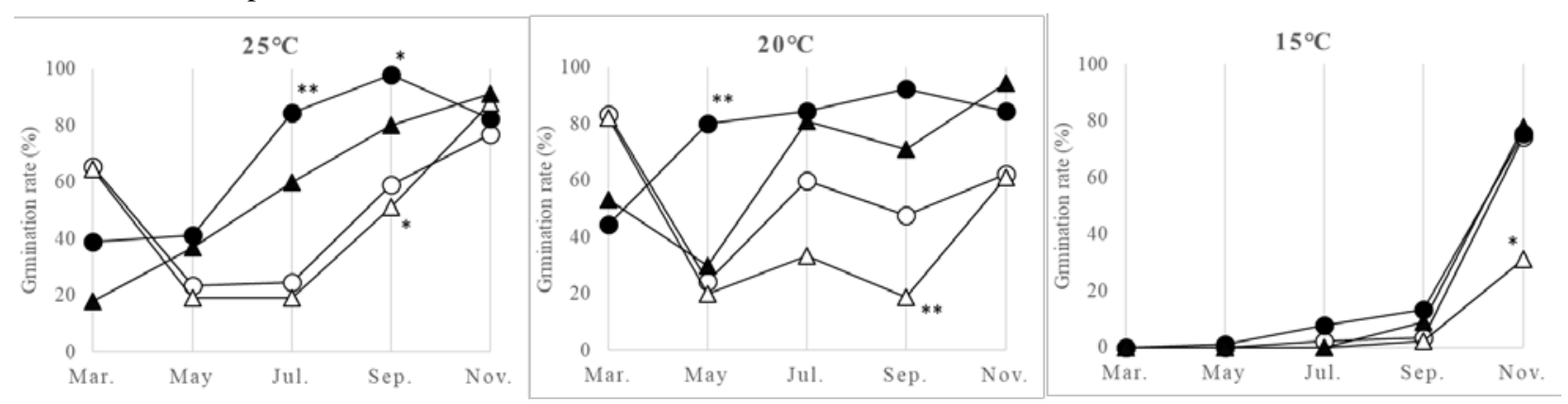

(O: Central achenes, light, $\triangle$ : Peripheral achenes, light, $\bullet$ Central achenes, dark, $\boldsymbol{\Delta}:$ Peripheral achenes, dark)

Figure 3. Seasonal change in the germination rate of central and peripheral achenes of Bidens pilosa $(* *$ and $*$ indicate a significant difference between the germination of central and peripheral achenes under the same conditions and on the same date at $1 \%$ and $5 \%$ level, respectively, according to the t-test).

\section{Discussion}

The seeds of B. pilosa are dispersed by animals, and the plant has heteromorphic achenes composed of central and peripheral achenes. Central achenes are more easily attached to surfaces such as animal hair than peripheral achenes. Indeed, it was observed that central achenes are detached earlier from the capitulum than peripheral achenes, which often remain on the capitulum fruit even during winter. B. frondosa possesses similar heteromorphic achenes, and its longer central achenes are considered to be better adapted to dispersal by animals [7]. In the present study, we revealed that compared to shorter peripheral achenes, longer central achenes can be detached from the capitulum significantly more easily. This suggested that central achenes may have a role to be dispersed to farther areas, whereas peripheral achenes may have a role to be dispersed to closer, neighboring areas. Further, the results of the present study indicated that central achenes, which are heavier, have a relatively high germination rate, whereas peripheral achenes, which are lighter, have a relatively low germination rate. It is known that there are differences in seed weight among the seed produced by the same plant [4, 15-17], and compared to heavier seeds, lighter seeds can become dormant more easily and have lower germination rates [18]. In addition, in the present study, central achenes with large seed weight showed higher germination rates than peripheral achenes with small seed weight. Similar difference in germination between central and peripheral achenes have already been investigated in other Bidens species [6-11]. As in the case of Bidens species, the cocklebur (Xanthium pennsylvanicum) has heteromorphic seeds dispersed by animals [19]. This species has fruits that have a longer seed and a shorter seed, and the shorter seed becomes dormant more easily and has a lower germination rate. The results we obtained for B. pilosa were similar to those obtained for cocklebur as in both species, the smaller seeds become dormant more easily than the larger seeds. Previous studies have reported that in the species with heteromorphic seeds, the seeds with a low dispersal ability have high seed dormancy, whereas the seeds with high dispersal ability showed reduced dormancy [20, 21]. It has been suggested that any morphological variation contributes to variation in dispersal distance [22], and any variation in dormancy contributes to variation in germination time [23, 24]. Consequently, differences in morphology and in the level of achene dormancy enable their emergence to be asynchronous in space and time [25]. In addition, Rocha [11] considered the central achenes of B. pilosa as long-distance 
dispersal units which must be ready to germinate upon arrival in a new environment. He called their dispersal a high-risk strategy because it might be hazardous to germinate quickly in unpredictable habitats. As peripheral achenes of B. pilosa are less likely to disperse and have a narrower range of temperatures suitable for germination, their dispersal was considered as a low risk strategy [11]. Our data provided the evidence that different types of achenes have different dispersal strategies. However, as B. pilosa is an annual plant species, the parent plant of B. pilosa is already dead in spring, when the seeds germinate. The purpose of the observed deep dormancy of the seed morphs dispersed near the parent plant is unclear.

It was reported that the stored seeds of weed species showed a cycle of dormancy [26-29]. In our results, the achenes of B. pilosa showed a seasonal change in germination rate. There is a difference in photoblastic germination of cocklebur seeds: longer seeds have light-induced germination, and shorter seeds have dark-induced germination [30]. In contrast, there is no difference in photoblastic germination between the two achene morphs of $B$. pilosa. The photoblastic germination in B. pilosa varies depending on the season, and both central and peripheral achenes in B. pilosa show light-induced germination in March and dark-induced germination from May to September. Under natural conditions, the achenes of B. pilosa could be on the soil surface in March, and in May, they could be in the soil after tillage or they could be on the soil surface under the light transmitted by the newly developed plant canopy. However, the adaptive significance changes in photoblastic of germination are not clear. Further studies are required for assessing this interesting phenomenon of seasonal variation in photoblastic germination.

Although in dark conditions, the central achenes had a high germination rate only at $20^{\circ} \mathrm{C}$ in May, they had a high germination rate at both $20^{\circ} \mathrm{C}$ and $25^{\circ} \mathrm{C}$ in July. Similarly, although in dark conditions, peripheral achenes had relatively higher germination rate at $20^{\circ} \mathrm{C}$ than at $25^{\circ} \mathrm{C}$ in July, they had a similarly high germination rate at $20^{\circ} \mathrm{C}$ and $25^{\circ} \mathrm{C}$ in September. In addition, in dark conditions, both central and peripheral achenes had a high germination rate at all temperatures, including $15^{\circ} \mathrm{C}$. This indicated that the temperature range at which these achenes are able to germinate increases with the increase in storage period. Because it has been suggested that the expansion of germination temperature range is related to the awakening of dormancy [31], it is supposed that the dormancy of achenes achenes of B. pilosa gradually released as the stored time period becomes longer.

In the surveyed area (Shizuoka, Japan), the emergence of B. pilosa was observed from spring to autumn (personal observation). The average temperature in Shizuoka is about $20^{\circ} \mathrm{C}\left(19.8^{\circ} \mathrm{C}\right)$ in May and about $25^{\circ} \mathrm{C}\left(25.2^{\circ} \mathrm{C}\right)$ in July (Japan meteorological agency. 2020). Only central achenes showed a high germination rate at $20^{\circ} \mathrm{C}$ in May, whereas both central and peripheral achenes showed a high germination rate at $25^{\circ} \mathrm{C}$ in July. This indicated that in dark conditions, central achenes germinate first (in May), and peripheral achenes germinate later (in the summer). In November, the temperature in Shizuoka is about $15^{\circ} \mathrm{C}\left(15.2^{\circ} \mathrm{C}\right)$ [32]. Our results showed both central and peripheral achenes had a high germination rate at $15^{\circ} \mathrm{C}$, regardless of the light/dark conditions. This indicated that B. pilosa might have a strategy in which all ungerminated seeds germinate before winter, without creating a seed bank.

\section{References}

[1] Baskin, J. M., J. J. Lu, C. C. Baskin, D. Y. Tan, and L. Wang. (2014). Diaspore dispersal ability and degree of dormancy in heteromorphic species of cold deserts of northwest China: a review. Persp. Plant Ecol. Evol. Syst., 16: 93-99. DOI: 10.1016/j.ppees.2014.02.004.

[2] Zhang, K., L. Yao, Y. Zhang, and J. Tao. (2019). Achene heteromorphism in Bidenspilosa (Asteraceae): differences in germination and possible adaptive significance. AoB Plants, 11(3): 1-8. DOI: 10.1093/aobpla/plz026.

[3] Becker, W. (1913). Über die KeimungverschiedenartigerFrüchte und Samenbeiderselben Species. Beih. Bot. Centralbl., 29: 49-52.

[4] Harper, J. L., P. H. Lovell, and K. G. Moore. (1970). The Shapes and Sizes of Seeds Annu. Rev. Ecol. Evol. Syst., 1: 327-356. DOI: 10.1146/annurev.es.01.110170.001551.

[5] Imbert, E. (1999). The effects of achene dimorphism on the dispersal in time and space in Crepis sancta (Asteraceae). Can. J. Bot., 77: 508-513. DOI: 10.1139/cjb-77-4-508.

[6] Dakshini, K. M. M. and S. K. Aggarwal. (1974). Intracapitularcypsele dimorphism and dormancy in Bidensbipinnata. Biol. Plant., 16: 469-471. DOI: 10.1007/BF02922239.

[7] Brändel, M. (2004). Dormancy and germination of heteromorphic achenes of Bidensfrondosa. Flora, 199: 228-233. DOI: 10.1078/0367-2530-00150.

[8] Felippe, G. M. (1990). Germinaçao de Bidens gardener Baker, uma planta anual dos cerrados. Hoehnea, 17: 7-11.

[9] Corkidi, L., E. Rincon, and C. Vazquez-Yanes. (1991). Effects of light and temperature on germination of heteromorphic achenes of Bidensodorata (Asteraceae). Can. J. Bot., 69: 574-579. DOI: 10.1139/b91-078.

[10] Forsyth, C. and N. A. C. Brown. (1982). Germination of the dimorphic fruits of Bidenspilosa L. New Phytol., 90: 151-164. DOI: $10.1111 / j .1469-8137.1982 . t b 03248 . x$. 
[11] Rocha, O. J. (1996). The effects of achene heteromorphism on the dispersal capacity of Bidenspilosa L. Int. J. Plant Sci., 157: 316-322. DOI: 10.1086/297351.

[12] National Institute for Environmental Studies. (2020). Available from: https://www.nies.go.jp/biodiversity/invasive/ DB/detail/80460.html [Accessed 21 August 2020].

[13] Holm, L. G., D. L. Plucknett, J. V. Pancho, and J. P. Herberger. (1977). The world's worst weeds: distribution and biology. Honolulu, University Press of Hawaii. ISBN: 0824802950.

[14] Gutterman, Y. (2002). Survival strategies of annual desert plants. Berlin, Springer-Verlag. ISBN: 978-3-540-43172-5.

[15] Gray, D. and T. H. Thomas. (1982). Seed germination and seedling emergence as influenced by the position of development of the seed on, and chemical applications to, the parent plant. In: The physiology and biochemistry of seed development, dormancy and germination, Khan, A.A., (Ed.). New York, Elsevier. pp: 81-110. ISBN: 0444804234.

[16] Gutterman, Y. (1981). Annual rhythm and position effect in the germinability of Mesembryanthemum nodiflorum. Israel J. Bot., 29: 93-97. DOI: 10.1080/0021213X.1980.10676879.

[17] Salisbury, E. J. (1942). The reproductive capacity of plants. London, G. Bell and Sons.

[18] Yoshioka, T., Y. Yamasue, and K. Ueki. (1985). Seed ecological studies in relation to the asynchronous emergence of EchinochloaoryzicolaVasing. 1. Variations in weight and ripening date of seeds among setting positions within one plant. J. Weed Sci. Tech., 30: 58-64. DOI: 10.3719/weed.30.58. (in Japanese)

[19] Esashi, Y., R. Kuraishi, N. Tanaka, and S. Satoh. (1983). Transition from primary dormancy to secondary dormancy in cocklebur seeds. Plant Cell Environ., 6: 493-499. DOI: 10.1111/1365-3040.ep11588130.

[20] Imbert, E. (2002). Ecological consequences and ontogeny of seed heteromorphism. Perspect. Plant Ecol. Evol. Syst., 5: 13-36. DOI: $10.1078 / 1433-8319-00021$.

[21] Olivieri, I. and A. Berger. (1985). Seed dimorphism for dispersal, physiological and demographic aspects. In: Genetic Differentiation and Dispersal in Plants, Jacquard, P., G. Heim and J. Antonovics, (Eds.). Berlin, Springer. pp: 413-429. ISBN: 978-3-642-70839-8.

[22] Greene, D. F. and E. A. Johnson. (1989). A model of wind dispersal of winged or plumed seeds. Ecology, 70: 339-347. DOI: 10.2307/1937538.

[23] Baskin, C. C. and Baskin J. M. (1998). Seeds—Ecology, Biogeography and Evolution of Dormancy and Germination. - Acad. Pr., San Diego.

[24] Booth, B. D., S. D. Murphy, and C. J. Swanton. (2003). Weed Ecology in Natural and Agricultural Systems. Wallingford, CABI Publishing. ISBN: 0851995284.

[25] Hughes, P. W. (2018). Minimal-risk seed heteromorphism: proportions of seed. morphs for optimal risk-averse heteromorphic strategies. Front. Plant Sci., 9: 1412. DOI: 10.3389/fpls.2018.01412.

[26] Froud-Williams, R. J., D. S. H. Drennan, and R. J. Chancellor. (1984). The influence of burial and drestorage upon cyclic changes in dormancy, germination and response to light in seeds of various arable weeds. New Phytol., 96: 473-481. DOI: 10.1111/j.1469-8137.1984.tb03581.x.

[27] Fround-Williams, R. J., J. R. Hilton, and J. Dixon. (1986). Evidence for an endogenous cycle of dormancy in dry stored seeds of Poatrivialis L. New Phytol., 102: 123-131. DOI: 10.1111/j.1469-8137.1986.tb00804.x.

[28] Milberg, P. and L. Andersson. (1997). Seasonal variation in dormancy and light sensitivity in buried seeds of eight annual weed species. Can. J. Bot., 75: 1998-2004. DOI: 10.1139/b97-911.

[29] Dyer, W. E. (1995). Exploiting Weed Seed Dormancy and Germination Requirements through Agronomic Practices. Weed Sci., 43: 498-503. DOI: 10.1017/s0043174500081534.

[30] Esashi, Y., N. Ishihara, R. Kuraishi, and H. Kodama. (1983). Light Actions in the Germination of Cocklebur Seeds: I. Differences in the light responses of the upper and lower seeds. J. Exp. Bot., 34: 903-914. DOI: 10.1093/jxb/34.7.903.

[31] Vegis, A. (1964). Dormancy in higher plants. Annu. Rev. Plant Physiol., 15: 185-224. DOI: 10.1146/annurev.pp. 15.060164.001153.

[32] Japan meteorological agency. (2020). Available from: http://www.jma.go.jp/jma/menu/menureport.html [Accessed 21 August 2020]. 